\title{
Decline of groundwater table in Beijing and recognition of seismic precursory information*
}

\author{
Mingbo Yang ${ }^{1,2,3, \uparrow}$ Yuehu Kang ${ }^{1}$ and Qing Zhang ${ }^{4}$ \\ ${ }^{1}$ Institute of Geographic Sciences and Natural Resource Research, Chinese Academy of Sciences, \\ Beijing 100101, China \\ ${ }^{2}$ Graduate University of Chinese Academy of Sciences, Beijing 100049, China \\ ${ }^{3}$ Earthquake Administration of Beijing Municipality, Beijing 100080, China \\ ${ }^{4}$ Beijing Beifang Middle School, Beijing 100022, China
}

\begin{abstract}
This paper quantitatively analyzed groundwater table fluctuations caused by groundwater overdraft, and probed into the possibility of drawing earthquake precursory information from groundwater table variations on the background of groundwater overdraft. Main effect factors of groundwater regime in Beijing region include groundwater extraction and rainfall. The decline of groundwater table was directly related to regional groundwater overdraft. Using the method of correlation analysis, the paper analyzed the relation between groundwater overdraft and groundwater level variations, with the aim of evaluating the effect of groundwater overdraft on water levels in observation wells and providing scientific basis for identifying seismic precursory information. The results indicate that the variations of groundwater level in slightly-affected zones of groundwater overdraft can contain some seismic precursory information, and it is possible to extract seismic precursory anomalies if proper mathematical methods are adopted to remove the trend component and annual period changes.
\end{abstract}

Key words: groundwater table; overdraft; correlation analysis; seismic precursory anomaly CLC number: P315.72 3 Document code: A

\section{Introduction}

The capacity of predicting earthquake with subsurface fluid is still very limited (Che and Yu, 2004). With the development of economic construction in Beijing, groundwater extraction has caused a significant decline in groundwater table. It inevitably changed the regime of local groundwater, and decreased the sensitivity of groundwater level to reflect earthquake information, which has highly influence on the effectivity of earthquake monitoring and forecasting. With the increasing of depth and quantity of groundwater extraction wells, groundwater production increased continually and groundwater reserves was consumed more and more seriously. Groundwater could not get fully recharged, which results in changing of groundwater regime, dramatic drop of water levels, and disappearing of artesian wells. The situation formed a great threat for normal

\footnotetext{
* Received 27 March 2009; accepted in revised form 15 April 2009; published 10 June 2009.

- Corresponding author. e-mail: yangmb@bjseis.gov.cn
}

monitoring of seismic groundwater in Beijing (Department of Monitoring and Prediction, China Earthquake Administration, 2000; Che and Yu, 2004; Zhang and Li, 2005; Fan, 2003). In such a strong extraction region, whether does groundwater variation data include seismic precursory information? How to extract precursory information effectively? The solution to these problems is important to improve earthquake prediction in Beijing by fluid means.

\section{Effect of groundwater overdraft and evaluation}

2.1 Characteristics of gyrndwater regime in Beijing and its origin analysis

In Beijing, groundwater regime is affected by precipitation, extraction and other factors. High water table usually appears in the period from July to October annually, and low water table appears in the period from May to June annually. The groundwater table ranges $2-5 \mathrm{~m}$ annually. Groundwater regime is obviously influenced by precipitation and artificial exploitation. Groundwater 
table rises in rainy years and declines in dry years. However, groundwater table declines on the whole due to long time overdraft of groundwater (Figure 1). At the end of 2005, average depth of groundwater table in Beijing was $20.21 \mathrm{~m}, 1.17 \mathrm{~m}$ lower than that at the end of 2004, resulting in 600 million $\mathrm{m}^{3}$ reduction in groundwater reserves. Compared with that in 1980, groundwater table has dropped $12.97 \mathrm{~m}$, and the groundwater reserve has reduced 7.05 billion $\mathrm{m}^{3}$; compared with that in 1960 , the reserve has reduced 8.7 billion $\mathrm{m}^{3}$. Up to 2005 , groundwater table has declined continually for seven years since 1999. Average groundwater table depth reached $20.94 \mathrm{~m}$ in June of 2005, which is the maximal value in the records of the observation wells (Figure 1, Table 1) (Zhang and Li, 2005).

Table 1 lists annual precipitation, groundwater recharge, extraction and overdraft in Beijing over years. Groundwater extraction wells are mainly located in suburbs area, and their depths are in the range of 100-200 $\mathrm{m}$. Main groundwater extraction aquifer consists of Quaternary sediments. Using Matou well as an example, we analyzed the changes of groundwater level using correlation analysis method. The well is located in Tongzhou district, Beijing. Figure 1d shows the changes of groundwater level in the well. The depth of Matou well is $158 \mathrm{~m}$, and it is a mixed observation well of shallow phreatic water and deep confined water. Its observation aquifer consists of Quaternary sediments. The well is located in the groundwater runoff downstream of the Beijing area, and at the edge of groundwater cone formed by extraction. The groundwater table was significantly affected by rainfall and extraction. It is typical to reflect the trend of groundwater table variations in Beijing.

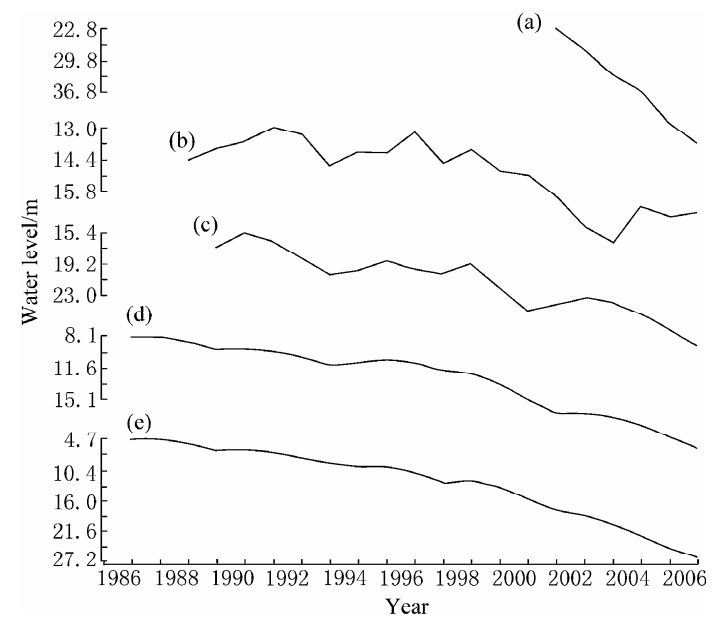

Figure 1 Dynamic curve of groundwater levels of wells Changping (a), Dahuichang (b), Xuxinzhuang (c), Matou (d) and Banqiao (e) in Beijing region for years.

Table 1 Variation of groundwater resources in Beijing region during the period from 1986 to 2005

\begin{tabular}{|c|c|c|c|c|c|c|}
\hline Year & $\begin{array}{l}\text { Precipitation } \\
/ \mathrm{mm}\end{array}$ & $\begin{array}{l}\text { Recharge volume } \\
\qquad / \mathrm{m}^{3}\end{array}$ & $\begin{array}{l}\text { Groundwater extrac- } \\
\text { tion volume } / \mathrm{m}^{3}\end{array}$ & $\begin{array}{l}\text { Groundwater over- } \\
\text { draft volume } / \mathrm{m}^{3}\end{array}$ & $\begin{array}{l}\text { Water level in } \\
\text { Matou well/m }\end{array}$ & $\begin{array}{l}\text { Variation amplitude } \\
\qquad / \mathrm{m}\end{array}$ \\
\hline 1986 & 560 & 16.54 & 28.17 & 11.63 & 8.1622 & 0.96 \\
\hline 1987 & 570 & 18 & 27 & 9 & 8.1332 & -0.029 \\
\hline 1988 & 590 & 19.58 & 21.02 & 1.44 & 8.6213 & 0.4881 \\
\hline 1989 & 480 & 13.57 & 20.1 & 7.47 & 9.547 & 0.9257 \\
\hline 1990 & 667 & 21.43 & 20.61 & -0.82 & 9.442 & -0.105 \\
\hline 1991 & 655 & 21.24 & 21 & -0.24 & 9.6658 & 0.2238 \\
\hline 1992 & 491 & 13.59 & 22 & 8.41 & 10.283 & 0.6172 \\
\hline 1993 & 423 & 12.28 & 23.56 & 11.28 & 11.2213 & 0.9383 \\
\hline 1994 & 724 & 28.6 & 25 & -3.6 & 10.989 & -0.2323 \\
\hline 1995 & 596 & 24.35 & 24.45 & 0.1 & 10.6493 & -0.3397 \\
\hline 1996 & 656 & 26.79 & 24.5 & 2.34 & 11.0148 & 0.3655 \\
\hline 1997 & 410 & 15.1 & 23.1 & 8 & 11.8512 & 0.8364 \\
\hline 1998 & 686 & 24.31 & 22.81 & -1.5 & 12.1518 & 0.3006 \\
\hline 1999 & 373 & 10.6 & 24.05 & 13.46 & 13.3081 & 1.1563 \\
\hline 2000 & 438 & 12.18 & 25.52 & 13.34 & 15.0552 & 1.7471 \\
\hline 2001 & 462 & 12.2 & 24.53 & 12 & 16.5494 & 1.4942 \\
\hline 2002 & 413 & 11.8 & 21.53 & 9.74 & 16.593 & 0.0436 \\
\hline 2003 & 453 & 12 & 21.59 & 9.59 & 17.0912 & 0.4982 \\
\hline 2004 & 539 & 15.2 & 22.19 & 7.0 & 17.821 & 0.7928 \\
\hline 2005 & 468 & 13.77 & 22.09 & 9.33 & 19.263 & 1.442 \\
\hline
\end{tabular}

Note: Data come from: (1) Beijing Water Affairs Bureau. Beijing Water Resources Bulletin (2000-2005); (2) Beijing Water Conservancy Hydropower Center. Beijing Agriculture Water Resources Data (1986-2002).

\subsection{Groundwater overdraft effect analysis}

There are direct relation between groundwater table variation and groundwater extraction condition. During the period of groundwater overdraft, groundwater extraction is greater than recharge, and some aquifer storage is consumed, resulting in groundwater table fall and 
appearance of groundwater cone. Recent years, rainfall in Beijing region was obviously less than normal year, and groundwater extraction was not able to get effective control. Thus, groundwater extraction has been greater than its recharge for many years. Groundwater overdraft becomes more and more seriously. Subsequently, regional groundwater table declines at a higher speed.

Table 1 lists that groundwater extraction in Beijing has kept steady since the late 1980s. After 1999, successive dry years and little rainfall aggravated the shortage of groundwater resources, and groundwater overdraft became serious during the period from 1999 to 2005. During the period, the rainfall decreased by $22 \%-37 \%$ compared with mean annual rainfall, and average annual groundwater extraction was 25 hundred million $\mathrm{m}^{3}$. The groundwater overdraft area covered most counties in Beijing.

Comparison of dynamic variation of annual mean rainfall, annual mean groundwater extraction, and annual overdraft and groundwater table curve in the Matou well are shown in Figure 2. It shows that there are close relation between region groundwater table decline and rainfall. Analysis on dependency relation between rainfall and annual variation amplitude of groundwater table for the Matou well, indicates that the correlative coefficient is $r=-0.652$ (observation data $N=20$, correlation analysis verification criterion $\alpha=0.05$, the same as other dependency relation); annual groundwater extraction has great effect on groundwater table in Beijing. Through calculation, this correlative coefficient between annual groundwater extraction and annual variation amplitude of groundwater table for the Matou well is $r=0.354$. Correlation analysis shows that the correlative coefficient between annual overdraft and annual variation amplitude of groundwater table for the Matou well is $r=0.7443$.

Through analysis on dependency relation between annual variation amplitude of groundwater table and annual rainfall, annual groundwater extraction, annual overdraft of groundwater in the Matou well, it was observed that there are closest relation between groundwater table and annual overdraft of groundwater. So groundwater overdraft is the most significant effect factor for the groundwater table in the Matou well, which reflects the trend of regional groundwater table variation on the whole. The above-mentioned analysis also demonstrated that groundwater overdraft is the most significant effect factor contributed to regional decline of groundwater table in Beijing. The above conclusion is objective, but the analysis on the relation between groundwater extraction and groundwater table in the Matou well can be unilateral.
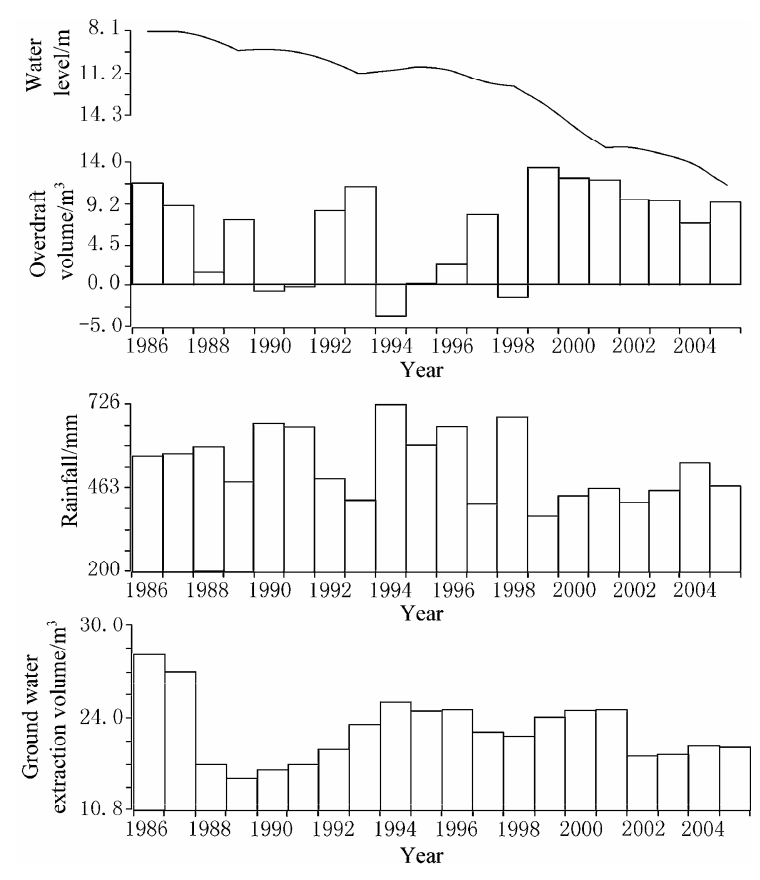

Figure 2 Comparison of dynamic variation of rainfall, groundwater extraction volume, overdraft volume in Beijing region with groundwater table in the Matou well during 1986 to 2005 .

\subsection{Effect evaluation of observation wells in groundwater overdraft regions}

It is very important to evaluate the effect of groundwater overdraft on groundwater level. The evaluation indicates that the effect of groundwater overdraft on observation wells is greater, and its disturbance to precursor of observation-well is greater. It is necessary to make the situation of observation wells in Beijing region clear: to what degree the groundwater overdraft disturbs earthquake precursor message; whether mid-term forecast can be made there. This research will provide scientific basis for earthquake prediction by use of observation wells, and for the layout of new observation wells.

The groundwater extraction in Beijing is characterized by that extraction wells distribute densely and exploit continually. Groundwater extraction has exceeded its recharge for a long time, resulting in groundwater table declining continually. Recent years, a sharp groundwater cone of depression was formed, and the declining speed at the center of the cone is faster than that at the edge of the cone (for example, water table 
decline in the Changping well was faster than that in the Matou well, Figure 2). Surrounding groundwater started to flow to the center of the cone (Figure 1) (Fang et al, 2005).

In order to evaluate the regional groundwater overdraft, the quantity of regional overdraft and the amplitude of groundwater table variations were both taken into consideration. The evaluation criterion was according to Beijing Water Resources Protection and Utilization Planning During Eleventh Five-year Plan Period by Beijing Water Affairs Bureau (2006) about division of groundwater overdraft area in Beijing region (Figure 3).



Figure 3 Distribution of groundwater overdraft situation in Beijing region (Beijing Water Affairs Bureau, 2006).

Some observation wells belong to serious overdraft area of groundwater such as the wells Changping, Banqiao, Xuxinzhuang, Liangxiang, and Yangdi. Groundwater extraction, especially hot groundwater extraction, increased rapidly in the area, which seriously influenced deep groundwater in bedrock-fracture. Since 2001, the annual decline amplitude of groundwater table is $6 \mathrm{~m}$ in the Changping well which was located at the center of the groundwater cone. The precursory information of observation wells in the area was seriously disturbed and precursory information could not be correctively presented.

Another observation wells were located at the edge of groundwater seriously overdrafted area (Figure 3) such as the wells Matou, Dahuichang, Fengtai, Zhaogezhuang, Xiaoshuiyu. Although groundwater table decline increased in recent years, they can still reflect some omen observation information. Among them, the wells Matou, Fengtai and Zhaogezhuang were affected by field irrigation extraction and water resources extraction; Dahuichang and Xiaoshuiyu wells, located at head water belt before mountain, were not affected by groundwater overdraft.

\section{Recognition of medium-strong earth- quake precursory information in the observation wells of overdraft region}

\subsection{Overview of medium-strong earthquakes}

Earthquakes in Beijing and its neighbor area almost distribute along the main seismic belt, including Yanshan seismic belt, Hebei plain seismic belt and Shanxi seismic belt. The medium-strong earthquakes occur in group and concentrate in time and space. The earthquake above $M_{\mathrm{S}} 5$ occurred with 10-year quasi-period. The earthquakes occur mostly at the intersection of the seismic belts.

3.2 Recognition of medium-strong earthquake anomaly precursory information

\subsubsection{Selection of recognition methods}

Although the characteristics of seismic precursory anomaly of groundwater table vary, for the trend anomaly, it usually appears as rise, decline or trend transition on the stable change background, and the most appears as rise (Wang et al, 2003).

On the situation of continuous groundwater overdraft and continual decline of groundwater level, it is feasible to extract the abnormity information on the background of groundwater level dynamic trend (Zhang et al, 2007; Yang et al, 2006) from the observation data of water level by the methods of removing trends and annual periodic changes. We extract the trend abnormity of Tongzhou, Matou, Fengtai and Dahuichang wells with subordinate function and variate-difference method in this paper. First, we pretreat the observation data of well water level: after smoothing the monthly mean data, take 23-point linear sliding average value (13-point sliding for variate-difference method) to remove high-frequency, short-term random changes and yearly periodic change and others. Then to treat the data with subordinate function and variant-difference method.

Subordinate function and variate-difference method are both used to remove yearly periodic change and short-term random changes, and extract the long-period change of groundwater level, which can express the relative change volume of ground fluid field, stress and strain field and the geophysical field. Multi-point synchronous abnormal changes reflect the characteristics of 
regional tectonic stress change (Liu et al, 2002).

\subsubsection{Recognition results and analysis}

By subordinate function and variate-difference method, we deal with the well groundwater level data in the serious overdraft areas of groundwater and the general overdraft areas. Taking Banqiao, Matou and Dahuichang wells as examples, their precursory anomaly information were extracted (Figures 4 and 5), from which we can know that though the groundwater level in Beijing declines year by year, trend turning or turn-rising in the process of decline can be significantly highlighted. For example, before the Zhangbei $M_{\mathrm{S}} 6.2$ earthquake on January 10, 1998, both Matou and Dahuichang wells have clear anomaly indicators, and the anomaly extracted by variate-difference method lagged that by subordinate function; before the Wen'an $M_{\mathrm{S}} 5.1$ earthquake in Hebei province on July 4, 2006, anomaly of Dahuichang well was also prominent, but water level in the Banqiao well did not show obvious abnormality due to effect of serious overdraft.
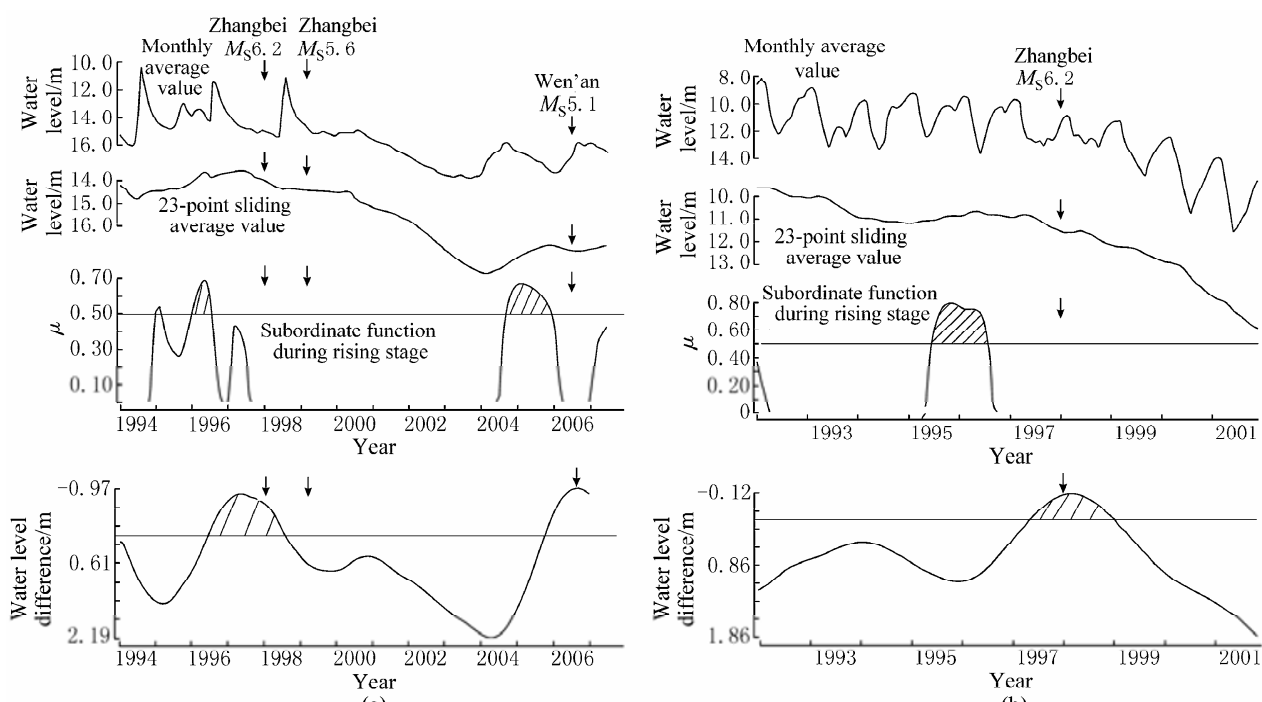

(b)

Figure 4 Water-level trend anomaly curve of the wells Dahuichang (a) and Matou (b).

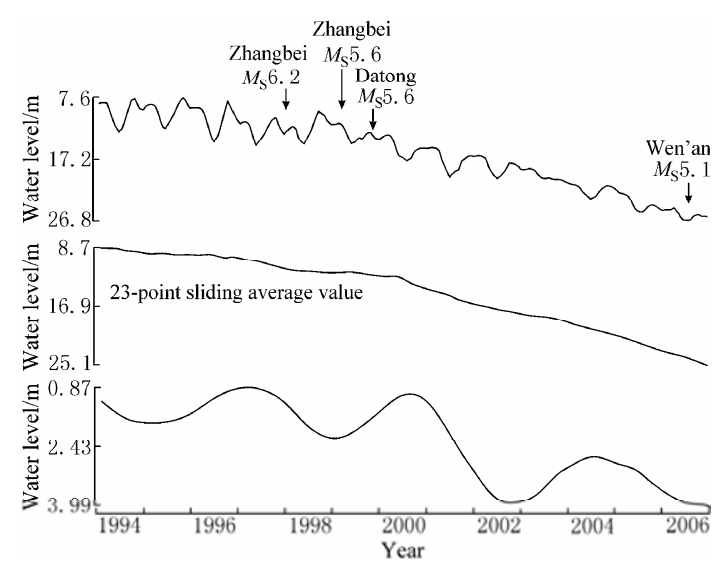

Figure 5 Groundwater level trend variation of the Banqiao well.

The above analysis shows that overdraft of these wells is too large; earthquake abnormal information is shielded and interfered severely. In the specific analysis, we can remove the serious overdraft wells after the evaluation. After treating the general groundwater overdraft wells by mathematic method, we can extract trend omen anomaly of groundwater level in Beijing before the medium-strong earthquake. These trends of omen anomalies appear multi-point simultaneously with other water level observation wells in the northern China, which is of certain periodicity (Zhang et al, 2007). And there are corresponding anomalies before the two significantly earthquake, suggesting that the omen abnormities can be verified.

\section{Discussion and conclusions}

Groundwater dynamical variation in Beijing is affected by precipitation, groundwater extraction, and regional tectonic activity. The interaction of groundwater level changes and tectonic activity is in favor of the earthquake formation and development, and also causes groundwater level precursory anomaly. For the hidden impact on regional tectonic activity, a wide range of analysis is needed to find the impact of tectonic activity using certain methods so as to identify seismic precursory information. 
1) Research results indicate that main reason for regional groundwater table declining in Beijing is attributed to heavy extraction of groundwater and decrease of precipitation for years. Because of the direct and powerful effect of groundwater overdraft on groundwater level, it is necessary to quantify the overdraft of groundwater when studying groundwater regime in Beijing.

2) Groundwater exploitation is widespread and regional groundwater overdraft causes the trend change of groundwater table. So, we can not do well in seismic fluid monitoring and seismic analysis if the precursory anomaly extraction problem was not resolved successfully on the background of groundwater extraction. On the basis of evaluating the effect of groundwater overdraft on observation wells in the groundwater overdraft areas, firstly remove the groundwater serious overdraft wells, then deal with the groundwater level observation data of general overdraft and un-overdraft wells, using the method such as subordination function and variate-difference to remove yearly periodic change and short-term random changes. Thus, we can extract medium and long-term precursory trend anomalies from groundwater table variations, which were influenced by regional groundwater overdraft.

3) When planning the seismic observation wells, seismic agencies should take groundwater overdraft into account and try to avoid the wells strongly affected by groundwater overdraft.

Acknowledgements The authors are grateful for guidance and help of Profs. Yongtai Che, Jiyi Wang,
Yaowei Liu and Chengqi Xing in this study. Thanks are also given to Jianfeng Yang for providing relevant information.

\section{References}

Beijing Water Affairs Bureau (2006). Beijing Water Resources Protection and Utilization Planning During Eleventh Five-year Plan Period. 42 (in Chinese).

Che Y T and Yu J Z (2004). The Investigation and Research of Underground Fluids Typical Anomaly. Seismological Press, Beijing, 20-60 (in Chinese with English abstract).

Department of Monitoring and Prediction, China Earthquake Administration (2000). The Guide to Earthquake Precursory Anomaly Investigation. Seismological Press, Beijing, 20-60 (in Chinese).

Fan J M (2003). Datong area groundwater-level dynamic research in recent twenty years. Groundwater 25(2): 95-97 (in Chinese).

Fang Y N, Lin X Y and Liao Z S (2005). The groundwater-level dynamic research and over-draft area identification in the plain area in Jilin. $H y$ drology 25(5): 19-22 (in Chinese with English abstract).

Liu Y W, Du J G and Wang C L (2002). Groundwater hydrochemical parameter medium and short-term precursory index system and forecasting effect evaluation. In: Luo L G, Han W B and Liu Y W eds. Strong Earthquake Medium and Short-term Forecasting Method and Effect Research. Seismological Press, Beijing, 180-211 (in Chinese).

Wang J Y, Song G Y, Cao Z C, Zheng Y Z, Zhang Z G, Fan X F, Huang F Q and Yang M B (2003). The mechanism of shallow layers anomaly caused by groundwater and its related question in earthquake prediction. North China Earthquake Science 20: 1-10 (in Chinese with English abstract).

Yang M B, Wang J Y, Liu X L, Wang L, Zhao W Z, LU Y and Zhang H K (2006). Study on recognition of fluid anomaly and its characteristics for moderately strong earthquakes in Beijing region and its adjacent area. Earthquake 26(3): 53-63 (in Chinese with English abstract).

Zhang S X, Liu Y W, Lu M Y and Zhang Z G (2007). Long tendency dynamic analysis of water level in groundwater overdrafting area. Earthquake 27(4): 51-58 (in Chinese with English abstract).

Zhang Z H and Li L R (2005). China Groundwater Resources (Beijing Volume). Sinomaps Press, Beijing, 1-60 (in Chinese). 